\title{
Effect of thickeners and sweeteners on the release of blended aroma compounds in fat-free stirred yoghurt during shear conditions
}

\author{
Nicolas Decourcelle $^{\mathrm{a}}$, Samuel Lubbers ${ }^{\mathrm{a}, *}$, Nadine Vallet ${ }^{\mathrm{b}}$, \\ Pascale Rondeau ${ }^{\mathrm{b}}$, Elisabeth Guichard ${ }^{\mathrm{a}}$ \\ a Unite Mixte de Recharche sur les Aromes, ENESAD-INRA, 17, rue de Sully Dijon Cedex F-21065, France \\ ${ }^{\mathrm{b}}$ UMA Danone Vitapole, RD128, Palaiseau Cedex 92767, France \\ Received 3 July 2003; accepted 18 February 2004
}

\begin{abstract}
The present study was conducted on aromatised fat-free stirred yoghurts and dealt with the influence of some thickeners and sweeteners on aroma compounds release and rheology.

Thickeners (starch, pectin, locust bean gum and guar) and sweeteners (fructose, fructo-oligosaccahrides, aspartame and acesulfame) were added and mixed together in fruit preparations, which were then introduced in yoghurt. Different concentrations of thickeners and sweeteners were used in the fruit preparations and were obtained with an experimental design. The headspace composition was assessed by solid-phase microextraction during shear conditions in a closed vessel. Rheological properties of yoghurts were determined to obtain the flow behaviour index $n$ and the consistency index $K$ with the Ostwald law.

The presence of pectin in yoghurts, tended to reduce the concentration of aroma compounds in the headspace of the samples. We observed also a significant decrease of aroma compounds in the headspace of yoghurt in the presence of starch. In the case of locust bean gum, a significant increase of flavour release was observed. Sweeteners and guar appeared to have no effect. We concluded that rheological parameters did not explain the difference on aroma release and it seemed that during shear conditions, the composition of fruit preparations showed a major role on aroma release. The influence of aroma compounds characteristics on the flavour release was observed, but experiments must be performed to highlight this observation.
\end{abstract}

(C) 2004 Elsevier Ltd. All rights reserved.

Keywords: Yoghurt; Thickeners; Flavour release; Rheology; Fat-free

\section{Introduction}

Eliminating fat modifies structure, texture, and flavour perception of food matrix (Dubois, Lubbers, \& Voilley, 1995; Tuorila, Sommardahl, \& Hyvönen, 1995; Hess, Roberts, \& Ziegler, 1997; Brauss, Linforth, Cayeux, Harvey, \& Taylor, 1999). Thickeners used as fat substitutes are generally added first in a fruit preparation or a syrup, which is then introduced in yoghurt. The effects of thickeners as fat substitute on rheological properties of fat-free yoghurt have been well studied (Ramaswamy \& Basak, 1992; Barrantes, Tamine, Davies \& Barclay, 1994; Kratz \& Dengler, 1995). However, few information has been obtained on the

*Corresponding author. Tel.: + 33-3-80-69-35-42; fax: + 33-3-80-7727-51.

E-mail address: s.lubbers@enesad.fr (S. Lubbers). impact of thickeners in aroma release from fat-free yoghurt and more is needed.

It is well known that thickeners can modify flavour release (Pangborn \& Szczesniak, 1974; Dubois et al., 1995). Pangborn and Szczesniak (1974) found a decrease on aroma perception by increasing pectin concentration and gel firmness. Roberts, Elmore, Langley and Bakker (1996) studied different solutions of similar viscosity with different thickener types and concluded that both viscosity and binding of flavour with the food matrix affect flavour release. Mälkki, Heiniö, and Autio (1993) found the same results with oat gum, guar gum and caroboxymethylcellulose, and showed that thickeners modified both the perceptions of flavour and sweeteners. In recent work, Rega, Guichard, and Voilley (2002) and, Lubbers and Guichard (2003) showed that in a pectin model gel with sugars, aroma compounds were retained through the three-dimensional network of pectin chains. 
In the case of starch, it is well known that amylose interacts with aroma compounds, but it is not obvious for amylopectin (Nuessli, Conde-Petit, Trommsdorff, \& Escher, 1995). More recently, it was shown, however, that ethyl hexanoate could interact with both amylose and amylopectin (Arvisenet, Voilley, \& Cayot, 2002).

Wendin, Solheim, Alimere, and Johansson (1997) tried to understand the effect of pectin, xanthan and gelatin in a acidified milk with or without fat on the perception of polar and non-polar aroma compounds. The authors showed that the thickeners introduced in their dairy products affected the aroma release as a function of the chemical characteristics of aroma compounds. For example, smell and flavour of maltol were unaffected by the thickeners studied, while smell and flavour of ethyl-2-methylbutyrate were affected.

The aim of this work was to study the impact of thickeners in an industrial stirred fat-free fermented milk on aroma release and on rheological properties during shearing. Fifteen aroma compounds with different physicochemical properties were chosen. Starch, pectin, locust bean gum (LBG) and guar gum were used as fat substitutes and were introduced in yoghurt via a fruit preparation. All products were assessed by headspace analysis with solid-phase microextraction (SPME) in a closed vessel. The flow properties were measured with a viscometer in order to follow the flow behaviour index $n$ and the consistency index $K$ with the Ostwald law $\left(\tau=K D^{n}\right)$, where $D$ is the shear rate $\left(\mathrm{s}^{-1}\right)$ and $\tau$ the shear stress $(\mathrm{Pa})$. The results are discussed in order to understand the role of thickeners in fermented stirred yoghurt based on actual data on polysaccharide-aroma compound interactions.

\section{Materials and methods}

\subsection{Headspace analysis of aroma compounds}

Analysis of volatile compounds was performed in a sealed system with a constant stirring of the sample. An aliquot of $80 \mathrm{~g}$ of product was inserted into a $150 \mathrm{~mL}$ closed double jacket vessel. The temperature was regulated with a circulating fluid at $35^{\circ} \mathrm{C}$. The top was closed with a cap lined with a Teflon seal. A screw-cap valve with Teflon seal allowed the sampling of the headspace of the vessel. According to the method described by Roberts and Acree (1995) the proportionality constant $k$ between the shear rate $(D)$ and the rotational speed $(S)$ for the stirrer $(D=k S)$ was measured on silicone oil $47 \mathrm{~V} 500$ RHODORSIL ${ }^{\circledR}$. According to those data, a shear rate of $100 \mathrm{~s}^{-1}$ (Roberts et al., 1996) in the headspace vessel was obtained with a rotational speed of $8.3 \mathrm{rps}$ (magnetic stirrer RET Control-Visc ${ }^{\circledR}$, circular bar $6 \times 12 \mathrm{~mm}$, IKA, Staufen,
Germany). The shearing of $100 \mathrm{~s}^{-1}$ may simulate chewing (Roberts et al., 1996).

A $65 \mu \mathrm{m}$ PDMS/DVB (polydimethylsiloxane-divinylbenzene) fibre was used to trap the aroma compounds in the headspace vessel during shearing. The fibre was introduced in the headspace vessel for 2 min at the start of shearing and, then was desorbed in a gas phase chromatograph injector at $250^{\circ} \mathrm{C}$ for $2 \mathrm{~min}$ for chromatographic analysis. After this period, the fibre was held at $250^{\circ} \mathrm{C}$ for $8 \mathrm{~min}$ to clean the fibre. Aroma compounds were analysed by gas chromatography (Hewlett-Packard $5890)$, using a splitless injection $\left(250^{\circ} \mathrm{C}\right)$ and a mass selective detector (5970-Hewlett-Packard, Palo Alto, CA). The quantification was realised by full-scan mode in the mass range from 29 to 330. A fused-silica capillary column, DB-Wax, $30 \mathrm{~m}, 0.32 \mathrm{~mm}$ i.d., $0.5 \mu \mathrm{m}$ film thickness (J\&W Scientific), was used with helium carrier gas (velocity $42 \mathrm{~cm} \mathrm{~s}^{-1}$ at $40^{\circ} \mathrm{C}$ ). The column was held at $40^{\circ} \mathrm{C}$ and the temperature increased at $3^{\circ} \mathrm{Cmin}^{-1}$ up to $120^{\circ} \mathrm{C}$ and $7^{\circ} \mathrm{C} \mathrm{min}^{-1}$ up to $220^{\circ} \mathrm{C}$.

\subsection{Rheology}

The flow behaviour index $(n)$ and the consistency factor $(K)$ were assessed using a coaxial cylinder viscometer $\left(\mathrm{RM} 180^{\circledR}\right.$ DIN 2:2, Rheometric Scientific, France) at $21^{\circ} \mathrm{C}$. As stirred yoghurt is a time- and sheardependent food product, the Benezech and Maingonnat (1992) and Schmitt, Ghnassia, Bimbenet and Cuvelier (1998) methods were applied. Those authors developed a rheological approach which allows to calculate $n$ and $K$ from theorical curves describing $\tau$ in function of time at different shear rates. We used the following shear rates : 64,180 and $250 \mathrm{~s}^{-1}$. A flow curve $(\eta=f(\tau))$ from those curves was then plotted and fitted with the Ostwald law $\left(\tau=K D^{n}\right)$ where $\eta$ is the apparent viscosity. Data "eta64" was the apparent viscosity $\eta$ measured at $10 \mathrm{~s}$, at $64 \mathrm{~s}^{-1}$ shear rate.

\subsection{Commercial stirred yoghurt}

Different batches of a same fat-free stirred yoghurt were delivered by the Danone company (France) during this experiment. To take into account the variability of industrial production, a reference sample with a certain composition and used as the centre-point of the experimental design, was analysed for each delivery. The variation coefficient was less than $10 \%$.

\subsection{Strawberry pulp, fat substitutes and sweeteners}

Strawberry pulp without akene was supplied by Danone. The whole quantity of strawberry pulp used for experiments came from the same batch of raw strawberry. The fat substitutes used were a lowmethoxyl (32-36\%) and low-amidated (14-18\%) pectin 
(CP Kelco, Denmark), a modified waxy corn starch with $1 \%$ amylose (National Starch, Belgium), a natural guar and a natural LBG both supplied by Degussa (France). A fructo-oligosaccharides syrup at $60 \%$ (FOS) and a fructose syrup at $95 \%$ of dry matter were used (Danone). Aspartame and potassium acesulfame powders were supplied by Arnaud group (France).

\subsection{Manufacturing of fruit preparations}

Thickeners, strawberry pulp, aspartame, acesulfame and water were added into the two sugar syrups (FOS and fructose) preheated at $85^{\circ} \mathrm{C}$ in a $500 \mathrm{~mL}$ jacked flask (circulating liquid: $95^{\circ} \mathrm{C}$ ), under stirring with a IKA ${ }^{\circledR}$ Power Control-Visco mixer equipped with an anchor at $250 \mathrm{rpm}$.After cooling down to $25^{\circ} \mathrm{C}$, the fruit preparations were stocked for $24 \mathrm{~h}$ at ambient temperature. Fruit preparations were introduced in yoghurt at a level of $20 \%(\mathrm{w} / \mathrm{w})$ and both were gently mixed under hygienic conditions. Fourteen fruit preparations were made. The amount of ingredients ranged between a low level and a high level fruit preparation (Table 2).

\subsection{Aroma compounds}

Table 1 shows the 15 aroma compounds blended in propan-1,2-diol which constitute a strawberry aroma (Firmenich S.A., International Headquarters, Geneva). The aroma was added at a concentration of $0.3 \mathrm{~g} \mathrm{~kg}^{-1}$ into the yoghurt containing a fruit preparation.

\subsection{Statisticlexperimental design}

An optimal experimental design was used to conduct this experiment and to determine which combination of each ingredient to use in yoghurts (shown in Table 2).

Table 1

Aroma compounds used for the strawberry flavour supplied by Firmenich

\begin{tabular}{ll}
\hline Aroma compound & CAS number \\
\hline Methyl 2-methylbutyrate & $868-57-5$ \\
Ethyl butyrate & $105-54-4$ \\
Ethyl hexanoate & $123-66-0$ \\
Butyl isovalerate & $109-19-3$ \\
Amyl butyrate & $540-18-1$ \\
Hexyl acetate & $142-92-7$ \\
Isoamyl isovalerate & $659-70-1$ \\
(Z) Hex-3-en-1-yl acetate & $3681-71-8$ \\
Hexan-1-ol & $25917-35-5$ \\
(Z) Hex-3-en-1-ol & $928-96-1$ \\
Benzyl acetate & $140-11-4$ \\
Methyl cinnamate & $103-26-4$ \\
Furaneol & $3658-77-3$ \\
Gamma-decalactone & $706-14-9$ \\
Methyl dihydrojasmonate & $24851-98-7$ \\
\hline
\end{tabular}

Table 2

Ingredient amounts for the low level fruit preparation and the high level fruit preparation (quantities are indicated in $\mathrm{g}$ per $100 \mathrm{~g}$ of fruit preparation)

\begin{tabular}{llc}
\hline Ingredients & Low level & High level \\
\hline Pectin & 0.25 & 1 \\
Starch & 0.5 & 1.5 \\
LBG & 0 & 0.1 \\
Guar & 0 & 0.1 \\
FOS & 7 & 20 \\
Fructose & 7 & 20 \\
Asp/Aces & 0.098 & 0.211 \\
Pulp & 47 & 47 \\
Water & 38.2 & 10.1 \\
\hline
\end{tabular}

Asp/Aces: quantities of aspartame and acesulfame — they were always incorporated together.

JMP 4.0.4 software (SAS Institute Inc.) was used to realise the experimental design treatment. Means of responses were used for the treatment of the experimental design. Normality and homogeneity of variance of results had to be checked with Shapiro-wilk and Levene tests, respectively. Following this step, after an evaluation of the size of the effects, the Lenth's method was used in order to reveal any statistically significant effect $(p<0.2)$.

The two principal component analyses (PCA) were realised with Statbox 6.1c sotfware (Grimmersoft). They highlight and explain results obtained and show the effect of sweeteners and thickeners on rheological parameters and on release of aroma compounds. Thickeners and sweeteners were indicated as additional variables.

\section{Results and discussion}

\subsection{Effects of the thickeners and sweeteners on rheological parameters of yoghurts}

The various yoghurts obtained from the experimental design treatment are presented in Table 3 in order of increasing apparent viscosity (eta64). The yoghurts A and $\mathrm{N}$ had high viscosities and contained the higher concentrations of thickeners. The relatively high to intermediate viscosities of samples labelled C, L, I, G, D corresponded with a low amount of starch or pectin in combination with the higher quantities of guar and/or LBG, or with the higher sugar content. Low viscosities of yoghurts labelled J, H, M, K and B could be due to low amounts of sweeteners and thickeners. It seemed that the viscosity of yoghurts was significantly high when the high pectin level was associated either at the high levels of starch, or guar/LBG, or FOS/fructose. In other associations, the viscosity of the products was lower. 
Table 3

Effect of the composition of fruit preparations in the 14 yoghurts on rheological parameters at $21^{\circ} \mathrm{C}$

\begin{tabular}{|c|c|c|c|c|c|c|c|c|c|c|c|c|c|}
\hline \multirow[t]{2}{*}{ Yoghurt } & \multicolumn{7}{|c|}{ g. $100 \mathrm{~g}^{-1}$} & \multirow[t]{2}{*}{$n$} & \multirow[t]{2}{*}{ SD } & \multirow[t]{2}{*}{$K\left(\mathrm{~Pa} \mathrm{~s}^{n}\right)$} & \multirow[t]{2}{*}{ SD } & \multirow[t]{2}{*}{ eta64 (Pa s) } & \multirow[t]{2}{*}{ SD } \\
\hline & Pectin & Starch & LBG & Guar & FOS & Fruc & Asp/Aces & & & & & & \\
\hline B & 0.05 & 0.1 & 0 & 0 & 1.4 & 1.4 & 0.042 & 0.492 & 0.023 & 3.78 & 0.45 & 0.389 & 0.008 \\
\hline $\mathrm{K}$ & 0.05 & 0.1 & 0 & 0.02 & 1.4 & 4 & 0.020 & 0.500 & 0.023 & 3.76 & 0.36 & 0.402 & 0.005 \\
\hline M & 0.05 & 0.1 & 0.02 & 0 & 4 & 1.4 & 0.020 & 0.500 & 0.023 & 3.76 & 0.36 & 0.422 & 0.012 \\
\hline $\mathrm{H}$ & 0.05 & 0.3 & 0 & 0.02 & 4 & 1.4 & 0.020 & 0.485 & 0.027 & 4.40 & 0.52 & 0.428 & 0.010 \\
\hline $\mathbf{J}$ & 0.05 & 0.1 & 0 & 0.02 & 4 & 4 & 0.042 & 0.465 & 0.014 & 4.88 & 0.39 & 0.445 & 0.002 \\
\hline $\mathrm{F}$ & 0.05 & 0.3 & 0.02 & 0 & 1.4 & 4 & 0.042 & 0.493 & 0.010 & 4.75 & 0.18 & 0.489 & 0.005 \\
\hline $\mathrm{D}$ & 0.05 & 0.3 & 0.02 & 0.02 & 4 & 1.4 & 0.020 & 0.507 & 0.004 & 4.43 & 0.12 & 0.490 & 0.003 \\
\hline $\mathrm{G}$ & 0.2 & 0.1 & 0.02 & 0.02 & 1.4 & 4 & 0.020 & 0.427 & 0.028 & 6.78 & 0.90 & 0.514 & 0.006 \\
\hline $\mathrm{E}$ & 0.2 & 0.1 & 0 & 0 & 4 & 1.4 & 0.020 & 0.454 & 0.010 & 6.50 & 0.26 & 0.539 & 0.002 \\
\hline I & 0.2 & 0.3 & 0 & 0 & 1.4 & 1.4 & 0.020 & 0.454 & 0.011 & 6.28 & 0.44 & 0.568 & 0.017 \\
\hline $\mathrm{L}$ & 0.2 & 0.1 & 0.02 & 0.02 & 4 & 1.4 & 0.042 & 0.465 & 0.026 & 6.09 & 0.79 & 0.573 & 0.011 \\
\hline $\mathrm{C}$ & 0.2 & 0.3 & 0 & 0 & 4 & 4 & 0.042 & 0.501 & 0.013 & 5.52 & 0.42 & 0.586 & 0.016 \\
\hline $\mathrm{N}$ & 0.2 & 0.3 & 0.02 & 0.02 & 1.4 & 1.4 & 0.042 & 0.395 & 0.005 & 9.60 & 0.29 & 0.670 & 0.007 \\
\hline
\end{tabular}

SD: standard deviation.

The yoghurts labelled with a letter, are arranged in order of increasing apparent viscosity (eta64). Quantities of thickeners and sweeteners are indicated in $\mathrm{g}$ per $100 \mathrm{~g}$ of final yoghurt.

Table 4

Results of the experimental design treatment : significant statistical results for ingredients responsible for the modification of rheological properties of yoghurts

\begin{tabular}{|c|c|c|c|}
\hline Rheology & Pectin & Starch & LBG \\
\hline eta64 (Pa s) & $p=0.02 \Omega$ & $p=0.12 \Sigma$ & $p=0.19$ 凤 \\
\hline$n$ (flow behaviour index) & $p=0.03 \Im$ & $p=0.03 \curvearrowright$ & $p=0.62 \preccurlyeq$ \\
\hline$K($ consistency index $)$ & $p=0.001 \gtrsim$ & $p=0.21 \lesssim$ & $p=0.21 \Omega$ \\
\hline
\end{tabular}

Significant effect if $p<0.2$ (Lenth's method); হ হ: positive effect; §: negative effect.

Table 4 shows the statistical results of experimental design for rheological characteristics. In agreement with the literature, it showed that pectin, starch and LBG had significant and positive effects on the apparent viscosity eta64 and the consistency index $K$; they had a negative effect on the flow behaviour index $n$ (Barrantes et al., 1994; Kratz \& Dengler, 1995; Keogh \& O'Kennedy, 1998).

The PCA presented in Fig. 1 showed that the vectors representing the rheological variables were highly correlated with the axis 2 . The consistency index $K$ and the apparent viscosity eta64 were strongly correlated with the factor pectin $\left(r^{2}>0.90\right)$. Yoghurts, labelled with letters, were distributed on both sides of the axis 2. Yoghurts H, F, B, K and D were characterised by $n$, whereas yoghurts $\mathrm{N}, \mathrm{G}, \mathrm{L}$ and $\mathrm{E}$ were characterised by $K$. This result correlated with the composition of thickeners described above (Table 3). Indeed, yoghurts N, G, L, E, A contained the higher concentrations of thickeners. We noticed the very significant effect of pectin on the rheological parameters in comparison with the other thickeners. Kratz and
Dengler (1995) measured the yield stress $\left(\tau_{c}\right)$ of yoghurt without fat-containing fruit preparations using the model of Herschel-Bukley $\left(\tau=\tau_{\mathrm{c}}+K D^{n}\right)$. The authors showed that either an increase, or a reduction in $\tau_{\mathrm{c}}$ was observed dependent of the type of pectin introduced into the fruit preparation (in comparison with yoghurts containing fat). Ramaswamy et al. (1992) studied the impact of the quantity of a mixture of low methoxylated pectin and a raspberry concentrate on $K$ and $n$. They found that $K$ increased with increasing pectin and fruit concentrate. Wendin et al. (1997) showed that the incorporation of pectin increased the thickness of yoghurts.

\subsection{Effects of the thickeners and sweeteners on flavour release of yoghurts}

Table 5 presents the results of the experimental design treatment for the flavour release. It shows that only starch and LBG had a significant effect on release of aroma compounds. No effect for sweeteners and guar appeared (results not shown). Increasing starch concentration in yoghurt decreased the content of aroma compounds in the headspace, whereas the opposite effect was observed with LBG. Addition of low methoxyl pectin in yoghurt reduced aroma compounds concentrations in headspace, but its effect was not statistically significant. We noticed from the results presented in Table 5 that the release of alcohols into the headspace seemed less affected by changes in the composition of the fruit preparation than that of esters (see $p$ value $\gg 0.2$ ).

Results obtained with pectin were in accordance with the work of Wendin et al. (1997). As Rega et al. (2002) 


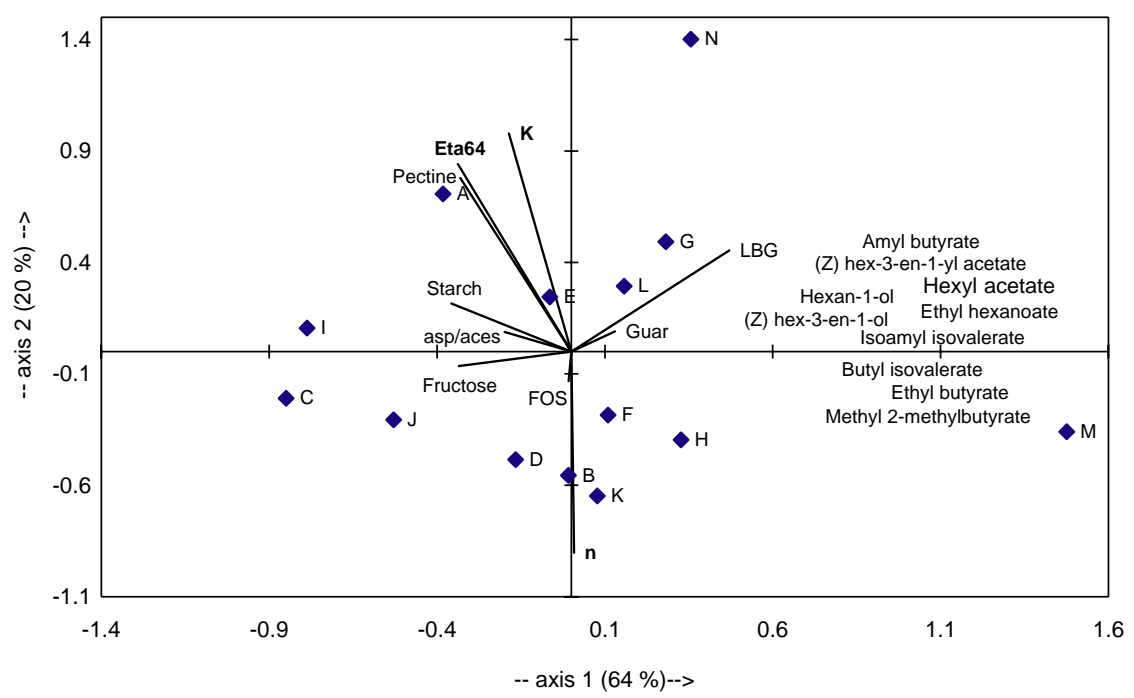

Fig. 1. PCA representing the aroma compounds release and the rheological parameters of yoghurts as affected by thickeners and sweeteners. Yoghurts are indicated by letters (see Table 3 for their composition). Vectors representing the rheological variables are highly correlated with the axis 2 and vectors representing the aroma compound release are highly correlated with the axis 1 .

Table 5

Results of the experimental design treatment: significant statistical results for ingredients responsible for the modification of aroma release in the headspace of yoghurts during shearing

\begin{tabular}{|c|c|c|c|}
\hline Aroma compounds & Pectin & Starch & LBG \\
\hline Methyl 2-methylbutyrate & $p=0.24 \bumpeq$ & $p=0.62 \varsigma$ & $p=0.25 \Omega$ \\
\hline Ethyl butyrate & $p=0.30 \varsigma$ & $p=0.57 \varsigma$ & $p=0.21 \bigotimes$ \\
\hline Ethyl hexanoate & $p=0.35 \varsigma$ & $p=0.15 \varsigma$ & $p=0.08 \Omega$ \\
\hline Butyl isovalerate & $p=0.31 \bumpeq$ & $p=0.19 \widehat{\Upsilon}$ & $p=0.08 \Omega$ \\
\hline Amyl butyrate & $p=0.35$ & $p=0.19 \widehat{\S}$ & $p=0.08 \Omega$ \\
\hline Hexyl acetate & $p=0.47 \bumpeq$ & $p=0.24 \widehat{\curlyvee}$ & $p=0.08 \Omega$ \\
\hline Isoamyl isovalerate & $p=0.38 \bumpeq$ & $p=0.23 \varsigma$ & $p=0.13 \Omega$ \\
\hline (Z) Hex-3-en-1-yl acetate & $p=0.47 \S$ & $p=0.17$ ऽ & $p=0.06 \gtrsim$ \\
\hline Hexan-1-ol & $p=0.70 \bumpeq$ & $p=0.19 \varsigma$ & $p=0.27$ 凤 \\
\hline (Z) Hex-3-en-1-ol & $p=0.80 乏$ & $p=0.43 \curlyvee$ & $p=0.24 \Omega$ \\
\hline Benzyl acetate & & nd & \\
\hline Methyl cinnamate & & nd & \\
\hline Furaneol & & nd & \\
\hline Gamma-decalactone & & nd & \\
\hline Methyl dihydrojasmonate & & nd & \\
\hline
\end{tabular}

Significant effect if $p<0.2$ (Lenth's method); $\Sigma$ : positive effect; §: negative effect; nd: not detected.

and Lubbers and Guichard (2003) showed, pectin decreases the diffusion of aroma compounds through the three-dimensional network of pectin chains and thus the release of flavour.

Molecular interactions between different starches and aroma compounds have been shown in the literature. Nuessli et al. (1995) and Cayot, Lafarge, Arvisenet, and Taisant (2000) observed a decrease in the release of aroma compounds from different matrices containing starches into the headspace. These authors showed that starch could trap some aroma compounds and include them. Although starch did not significantly affect the release of all the aroma compounds here, interactions between aroma compounds and starch must be not excluded.

The principal component analysis (Fig. 1) showed, that the vectors representing the aroma compound release were highly correlated with the axis 1 . The effect of LBG, however, did not correlate with that of starch and pectin. The yoghurts $\mathrm{M}$ and $\mathrm{B}$ contained the same amount of starch and pectin, but yoghurt $\mathrm{M}$ did contain LBG and yoghurt B did not. This difference could explain the location of sample $M$ on the positive part of the axis 1 in the same direction as the LBG vector. We suppose that LBG might have increased the release of aroma compounds by means of a salting-out effect as shown by Oakenfull and Scott (1984) in pectin gels. Galactomannanes contain a great numbers of sugar units and they would, therefore, be able to trap a significant amount of water. The decrease of water available for aroma compounds may thus have increased their release.

\subsection{Effect of shear}

Fig. 1 shows that the vectors representing the rheological variables (axis 2) and the vectors representing the aroma compounds (axis 1) are orthogonal. No correlation between the rheological parameters and the release of aroma compounds was found (correlation coefficients between 0.06 and 0.2). We suppose that rheological parameters did not explain the differences observed between yoghurts on flavour release during shear conditions.

In Fig. 1, the samples $\mathrm{C}, \mathrm{I}$ and $\mathrm{J}$ are rather oppositely located as compared to the aroma compounds but they showed mutually different viscosities (Table 3 ). It thus seemed that the rheological characteristics of $\mathrm{C}, \mathrm{I}$ and $\mathrm{J}$ 


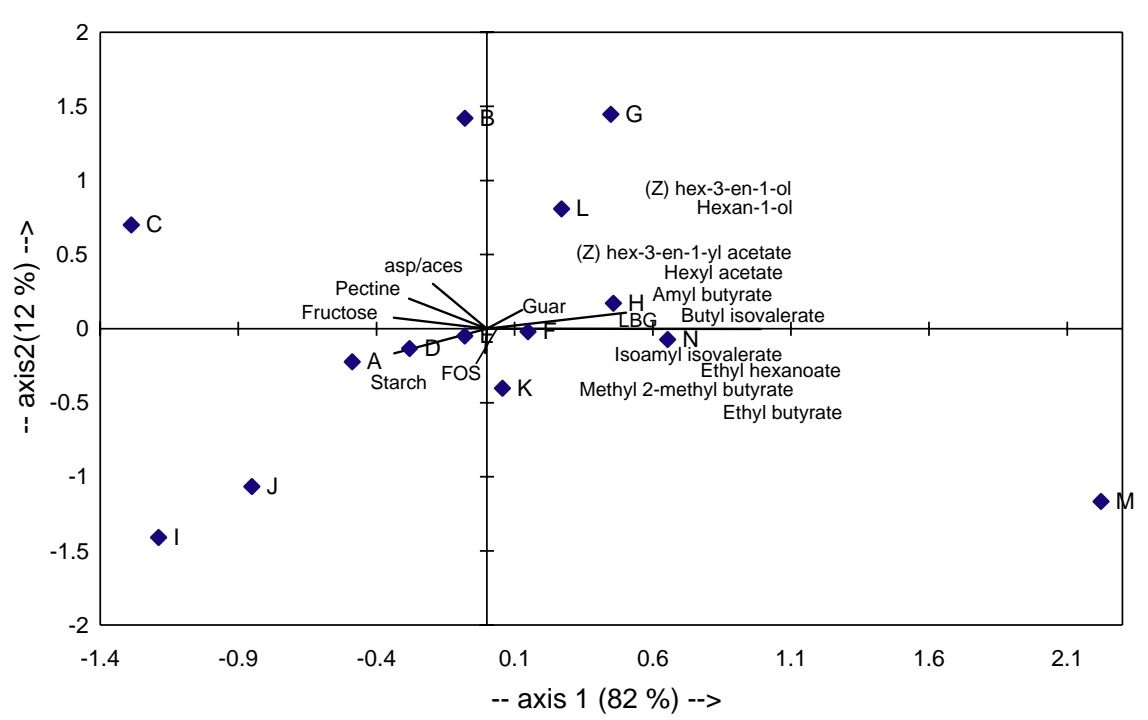

Fig. 2. PCA representing the aroma compounds release of yoghurts affected by thickeners and sweeteners. Yoghurts are indicated by letters.

yoghurts did not affect the release of aroma compounds, and interactions between the aroma compounds and thickeners seemed mainly responsible for the observed phenomenon. We are aware that many works showed that a decrease of flavour release would be explained by modifications in the rheology of matrices (Pangborn \& Szczesniak, 1974; Mälkki et al., 1993; Dubois et al., 1995; Rega et al., 2002). However, these results were generally obtained on model systems and without shear conditions. Contrary to that previous work, we measured flavour release under shear conditions and we used very low concentrations of thickeners and sweeteners, which are more realistic for industrial dairy products. Thus we conclude that the nature of ingredients in the fruit preparations could explain the differences in aroma release observed between yoghurts, and rheological parameters could not.

\subsection{Nature of aroma compound}

The principal component analysis presented in Fig. 2 was calculated on the data of the different samples with only the responses of aroma compounds as active variables. A separation was observed between esters and alcohols. The complexity of the yoghurts and the shearing during headspace analysis did not allow to distinguish between thickeners and/or shear as being responsible for this observation. But since no specific interactions of the alcohols and the esters with the ingredients used are known, it may be concluded that shear conditions and polarities of aroma molecules are responsible for this separation. Indeed, Roberts et al. (1996) showed that under shear conditions in model media containing polysaccharides (CMC and Guar), the release of aroma compounds is affected by their polarity. Aroma compounds with different polarities were also studied during shear conditions by Ingham, Linforth, and Taylor (1995). These authors observed that a deviant persistence of esters in the "nosespace" was related with their polarity.

The phenomena observed could be due both to the aroma compounds/polysaccharides interactions and the shear conditions. Since we had applied only one shear rate, complementary experiments will be necessary to dissociate the effect of molecular interactions from that of shear.

\section{Conclusion}

This study presented the effect of thickeners and sweeteners on the release of aroma compounds and on the rheology in industrial fat-free stirred yoghurts. Our objectives were to incorporate different concentrations of thickeners and sweeteners to observe their effects during shear conditions. Of all the factors studied, starch, pectin and LBG showed a significant statistical effect on aroma release. The results showed that the increase of the concentration of thickeners modified both aroma release and rheological parameters, but these modifications were not correlated. In other words, under shear conditions, the composition of yoghurts was mainly responsible for the release of aroma compound and the rheology but not for changes in eta64. $K$ and $n$ did not explain the differences in the flavour release of yoghurts.

The presence of polysaccharides in yoghurts tended to reduce the concentration of aroma compounds in the headspace of the samples. This effects on aroma release could be due to the interactions between polysaccharides and aroma compounds. In the case of starch, the molecular interactions between its helical chains and 
aroma compounds could cause a decrease of the concentration of aroma compounds in the headspace. The presence of LBG in yoghurts, increased significantly the flavour release, because LBG supposedly decreased the amount of available water and caused a salting-out effect. A difference between the release between alcohols and esters was observed. However, it will be necessary to endorse this observation with complementary work.

\section{Acknowledgements}

The authors thank the Firmenich society for having provided the strawberry aroma, and all the food ingredients suppliers we quoted for sweeteners and thickeners. We would also like to thank the Conseil Régional de Bourgogne for their financial support (research grant).

\section{References}

Arvisenet, G., Voilley, A., \& Cayot, N. (2002). Retention of aroma compounds in starch matrices: Competitions between aroma compounds toward amylose and amylopectin. Journal of Agricultural and Food Chemistry, 50, 7345-7349.

Barrantes, E., Tamine, A., Davies, G., \& Barclay, M. (1994). Production of low-calorie yogurt using skim milk powder and fat-substitutes. 2. Compositional quality. Milchwissenschaft, 49(5), 135-139.

Benezech, T., \& Maingonnat, J. (1992). Flow properties of stirred yogurt: Modelling and influence of cooling conditions. Theoritical and applied rheology, (pp. 613-695). Amsterdam: Elsevier Science Publishers.

Brauss, M. S., Linforth, R. S. T., Cayeux, I., Harvey, B., \& Taylor, A. J. (1999). Altering fat content affects flavor release in a model yogurt system. Journal of Agricultural and Food Chemistry, 47, 2055-2059.

Cayot, N., Lafarge, C., Arvisenet, G., \& Taisant, C. (2000). Influence of aroma compounds on the mechanical properties of starch-based food systems. Journal of Texture Studies, 31, 297-313.

Dubois, C., Lubbers, S., \& Voilley, A. (1995). Revue bibliographique: Interactions arômes autres constituants. Applications à l' aromatisation. Industries Alimentaires et Agricoles, 4, 186-193.

Hess, S., Roberts, R., \& Ziegler, G. (1997). Rheological properties of nonfat yogurt stabilized using Lactobacillus delbrueckii ss. bulgaricus producing exopolysaccharides or using commercial stabilizer systems. Journal of Dairy Science, 80, 252-263.

Ingham, K. E., Linforth, R. S., \& Taylor, A. J. (1995). The effect of eating on aroma release from strawberries. Food Chemistry, 54, 283-288.

Keogh, M., \& O'Kennedy, B. T. (1998). Rheology of stirred yogurt as affected by added milk fat, protein and hydrocolloids. Journal of Food Science, 63(1), 108-112.

Kratz, R., \& Dengler, K. (1995). Fruit preparations for yoghurts pectin as a thickener - requirements posed by producers of fruit preparations and yoghurts. Food Techology in Europe, June/July, 130-137.

Lubbers, S., \& Guichard, E. (2003). The effects of sugars and pectin on flavour release from a fruit pastille model system. Food Chemistry, 81(2), 269-273.

Mälkki, Y., Heiniö, R., \& Autio, K. (1993). Influence of oat gum, guar gum and carboxylmethyl cellulose on the perception of sweetness and flavor. Food Hydrocolloids, 6(6), 525-532.

Nuessli, J., Conde-Petit, B., Trommsdorff, U. R., \& Escher, F. (1995). Influence of starch flavour interactions on rheological properties of low concentration starch systems. Carbohydrate Polymers, 28, $167-170$.

Oakenfull, D., \& Scott, A. (1984). Hydrophobic interaction in the gelation of high methoxyl pectins. Journal of Food Science, 49, 1093-1098.

Pangborn, R. M., \& Szczesniak, A. S. (1974). Effect of hydrocolloids and viscosity on flavor and odor intensities of aromatic flavor compounds. Journal of Texture Studies, 4, 467-482.

Ramaswamy, H. S., \& Basak, S. (1992). Pectin and raspberry concentrate effects on the rheology of stirred commercial yogurt. Journal of Food Science, 57(2), 357-360.

Rega, B., Guichard, E., \& Voilley, A. (2002). Flavour release from pectin gels: Effects of texture, molecular interactions and aroma compounds diffusion. Science des Aliments, 22, 235-248.

Roberts, D., \& Acree, T. (1995). Simulation of retronasal aroma using a modified headspace technique: Investigating the effects of saliva, temperature, shearing, and oil on flavor release. Journal of Agricultural and Food Chemistry, 43(8), 2179-2186.

Roberts, D. D., Elmore, J. S., Langley, K. R., \& Bakker, J. (1996). Effects of sucrose, guar gum, and carboxymethylcellulose on the release of volatile flavor compounds under dynamic conditions. Journal of Agricultural and Food Chemistry, 44, 1321-1326.

Schmitt, L., Ghnassia, G., Bimbenet, J., \& Cuvelier, G. (1998). Flow properties of stirred yogurt: Calculation of the pressure drop for a thixotropic fluid. Journal of Food Engineering, 37, 367-388.

Tuorila, H., Sommardahl, C., \& Hyvönen, L. (1995). Does fat affect the timing of flavour perception? A case study with yoghurt. Food Quality and Preference, 6, 55-58.

Wendin, K., Solheim, R., Alimere, T., \& Johansson, L. (1997). Flavour and texture in sourmilk affected by thickeners and fat content. Food Quality and Preference, 8(4), 281-291. 